Atmos. Chem. Phys., 3, 1101-1111, 2003

www.atmos-chem-phys.org/acp/3/1101/

\title{
First observations of noctilucent clouds by lidar at Svalbard, $78^{\circ} \mathrm{N}$
}

\author{
J. Höffner, C. Fricke-Begemann, and F.-J. Lübken \\ Leibniz-Institut für Atmosphärenphysik, Kühlungsborn, Germany \\ Received: 23 October 2002 - Published in Atmos. Chem. Phys. Discuss.: 4 February 2003 \\ Revised: 29 April 2003 - Accepted: 5 June 2003 - Published: 1 August 2003
}

\begin{abstract}
In summer 2001 a potassium lidar was installed near Longyearbyen $\left(78^{\circ} \mathrm{N}\right)$ on the north polar island of Spitsbergen which is part of the archipelago Svalbard. At the same place a series of meteorological rockets ("falling spheres", FS) were launched which gave temperatures from the lower thermosphere to the stratosphere. The potassium lidar is capable of detecting noctilucent clouds (NLCs) and of measuring temperatures in the lower thermosphere, both under daylight conditions. In this paper we give an overview on the NLC measurements (the first at this latitude) and compare the results with temperatures from meteorological rockets which have been published recently (Lübken and Müllemann, 2003). NLCs were observed from 12 June (the first day of operation) until 12 August when a period of bad weather started. When the lidar was switched on again on 26 August, no NLC was observed. The mean occurrence frequency in the period 12 June - 12 August ("lidar NLC period") is $77 \%$. The mean of all individual NLC peak altitudes is $83.6 \mathrm{~km}$ (variability: $1.1 \mathrm{~km}$ ). The mean peak NLC altitude does not show a significant variation with season. The average top and bottom altitude of the NLC layer is 85.1 and $82.5 \mathrm{~km}$, respectively, with a variability of $\sim 1.2 \mathrm{~km}$. The mean of the maximum volume backscatter coefficient $\beta_{\max }$ at our wavelength of $770 \mathrm{~nm}$ is $3.9 \times 10^{-10} / \mathrm{m} / \mathrm{sr}$ with a large variability of $\pm 3.8 \times 10^{-10} / \mathrm{m} / \mathrm{sr}$. Comparison of NLC characteristics with measurements at ALOMAR $\left(69^{\circ} \mathrm{N}\right)$ shows that the peak altitude and the maximum volume backscatter coefficient are similar at both locations but NLCs occur more frequently at higher latitudes.

Simultaneous temperature and NLC measurements are available for 3 flights and show that the NLC layer occurs in the lower part of the height range with super-saturation. The NLC peak occurs over a large range of degree of saturation $(S)$ whereas most models predict the peak at $S=1$. This demonstrates that steady-state considerations may not be ap-
\end{abstract}

$\overline{\text { Correspondence to: F.-J. Lübken (luebken@iap-kborn.de) }}$ plicable when relating individual NLC properties to background conditions. On the other hand, the mean variation of the NLC appearance with height and season is in agreement with the climatological variation of super-saturation derived from the FS temperature measurements.

\section{Introduction}

Noctilucent clouds (NLCs) have been observed since more than 100 years in the upper summer mesosphere at polar and midlatitudes (Leslie, 1885; Gadsden and Schröder, 1989). The appearance of NLCs is closely connected to the very low temperatures in the summer mesopause region and is therefore indirect evidence for the peculiar seasonal variation of the thermal structure in the upper atmosphere ("cold" in summer and "warm" in winter) (von Zahn and Meyer, 1989; Lübken et al., 1996; Lübken, 1999). It was stated some years ago that the occurrence frequency of NLCs has increased in the last decades (Gadsden, 1998) and that this is perhaps related to anthropogenic changes (Thomas et al., 1989). More recently, however, it has been pointed out that this increase is presumably due to a bias in the data base and that there is in fact no trend present (Kirkwood and Stebel, 2003), which is in line with the observation that temperatures in the high latitude summer mesopause region do not show a long term trend (Lübken, 2000). Whether or not NLCs are an indicator for long term trends in the upper atmosphere can only be solved if we better understand the physical processes leading to NLCs and their relationship to the background conditions such as temperature and water vapor concentration.

The experimental investigation of NLCs has been significantly improved by lidars, which can now detect them even during full daylight (Hansen et al., 1989; von Zahn et al., 1998; Fricke-Begemann et al., 2002). A series of NLC observations at different locations, different wavelengths, and different observational setups has become available in the

(C) European Geosciences Union 2003 


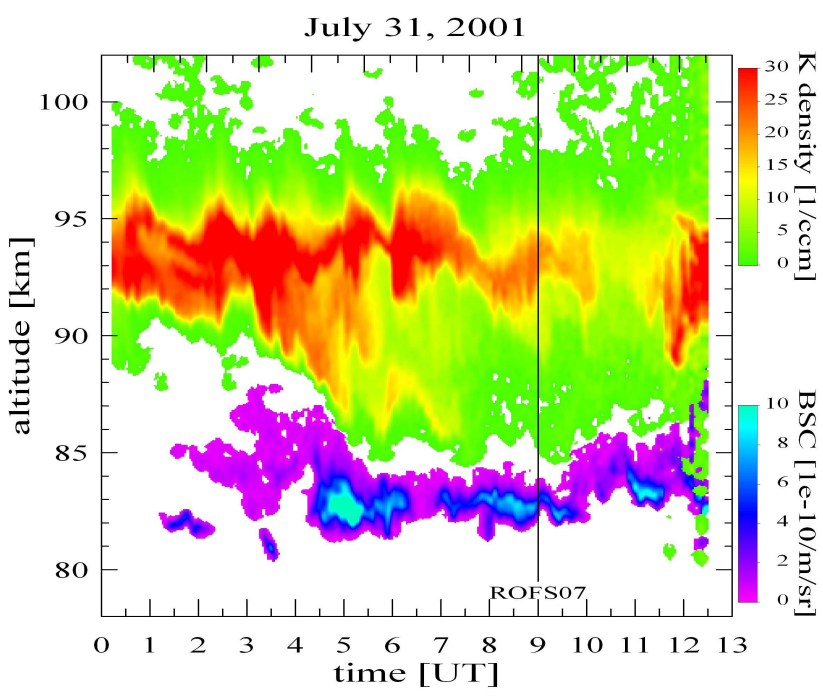

Fig. 1. Measurements of the K lidar on 31 July 2001. The potassium number density is shown in color contour from green to red, and the BSC from the NLC is shown in color contour from purple to blue (see color code at right margin). The maximum BSC observed around 5:00 UT was $20.8 \cdot 10^{-10} / \mathrm{m} / \mathrm{sr}$. The vertical line indicates the launch time of the falling sphere ROFS07.

last years (von Cossart et al., 1999; Alpers et al., 2000; Chu et al., 2001; Thayer et al., 2002; Baumgarten et al., 2002). These observations have significantly improved our knowledge about the nature of NLCs and have initiated various model studies to better understand the microphysical processes leading to their genesis including the dependence on background conditions varying with time, height, latitude, and longitude (Jensen and Thomas, 1988; Garcia, 1989; Fritts et al., 1993; Klostermeyer, 1998; Berger and von Zahn, 2002; Rapp et al., 2002). A critical test of some of these models comes from observations of NLCs at different latitudes which (if greater than approximately $60^{\circ}$ ) is only possible with lidars since the sky is too bright to observe NLCs by the naked eye.

In this paper we report on the first observations of NLCs by a potassium lidar on Svalbard $\left(78^{\circ} \mathrm{N}\right)$. These observations will be compared with measurements of the thermal structure in the upper mesosphere region by means of meteorological rockets ("falling spheres", FS). First results of these flights have been published in Lübken and Müllemann (2003) and some comparison with NLC and PMSE (polar mesosphere summer echoes) has been presented in Lübken et al. (2002). In the next section we describe the experimental techniques, namely the detection of NLCs with lidar, and the temperature measurements by meteorological rockets. In Sect. 3 we present the experimental data relevant to NLCs. A comparison of our results with measurements at other latitudes and the geophysical implications are discussed in Sect. 4.

\section{Experimental techniques}

\section{$2.1 \quad$ K lidar}

The mobile potassium resonance lidar of the IAP was designed to measure atmospheric temperatures and potassium abundance in the mesopause region $(80-105 \mathrm{~km})$. With a narrowband alexandrite laser the $K\left(D_{1}\right)$ resonance line at $769.9 \mathrm{~nm}$ is probed scanning the laser wavelength by a few pm over the Doppler broadened absorption line. From the spectral shape of the effective backscatter coefficient vertical profiles of air temperature and potassium density are derived. The instrument is described in more detail by von Zahn and Höffner (1996). Since November 2000 the lidar is provided with a Faraday anomalous dispersion optical filter for daylight rejection (Fricke-Begemann et al., 2002) which allows operation under polar summer conditions. The lidar was installed in spring 2001 at $78.23^{\circ} \mathrm{N}, 15.39^{\circ} \mathrm{E}$, near Longyearbyen, a small town on the north polar island of Spitsbergen which is part of the archipelago Svalbard.

Potassium lidar profiles are retrieved every $2 \mathrm{~min}$ and at $200 \mathrm{~m}$ intervals vertically. At altitudes between approximately $35 \mathrm{~km}$ and $120 \mathrm{~km}$ the lidar records the photons backscattered from air molecules, from the $\mathrm{K}$ layer, and from aerosols. A NLC is detected as an enhanced signal (relative to the background noise and the air molecule signal) which does not vary when the laser frequency is tuned over the potassium resonance line. The NLC is quantified by determining the volume backscatter coefficient (BSC) which is defined as:

$\beta_{N L C}(z, \lambda)=\left.n_{N L C}(z) \cdot \frac{d \sigma\left(180^{\circ}\right)}{d \Omega}\right|_{N L C}$

where $\mathrm{n}_{N L C}$ is the number density of NLC particles and $\left.\frac{d \sigma\left(180^{\circ}\right)}{d \Omega}\right|_{N L C}$ is the effective cross section for backscatter by an individual NLC particle for a specific NLC particle size distribution and the applied wavelength of $770 \mathrm{~nm}$. An expression analogous to Eq. (1) applies for scattering on air molecules $\left(\beta_{m}\right)$. In practice the backscatter coefficient is calculated from the backscatter ratio $R_{N L C}(z)$ and from $\beta_{m}$ by:

$\beta_{N L C}(z)=\left(R_{N L C}(z)-1\right) \cdot \beta_{m}(z)$

where the backscatter ratio $R_{N L C}(z)$ is determined from the backscatter signals

$R_{N L C}(z)=\frac{S(z)}{S_{\mathrm{m}}(z)}$.

$S(z)$ is the total signal (molecular plus NLC) after subtraction of the background, and $S_{m}(z)$ is the backscatter signal from the molecules. The molecular backscatter coefficient $\beta_{m}(z)$ in Eq. (2) is calculated as follows: Between 40 and $60 \mathrm{~km}$ the backscatter signal $S=S_{m}$ (there are no aerosols or K atoms at these heights) is normalized to the molecular backscatter signal, i. e. $S_{m}=c \cdot \beta_{m}$, which is calculated from the air 
densities taken from CIRA-1986 (Fleming et al., 1990). The constant $c$ constrains $\beta_{m}(z)$ at NLC altitudes. The NLC signal can be distinguished from the backscatter by $\mathrm{K}$ atoms as it is constant in wavelength. Thus the backscatter coefficients for both can be determined simultaneously. The ability to separate a NLC from the K layer depends on the strength of the NLC relative to the potassium signal. Generally, a strong $\mathrm{K}$ signal reduces the sensitivity to detect a NLC, and vice versa. For example, a NLC with a volume backscatter coefficient of $1 \cdot 10^{-10} / \mathrm{m} / \mathrm{sr}$ can be detected in a $\mathrm{K}$ layer with a density of up to $\sim 7 / \mathrm{cm}^{3}$.

In Fig. 1 the NLC and the potassium number densities on 31 July 2001, are shown. The potassium layer spreads over a height range of approximately $85-100 \mathrm{~km}$ and is clearly separated from the NLC. The NLC layer is present nearly permanently after 01:00 UT. The maximum BSC $\left(\beta_{\max }\right)$ appears at a fairly constant altitude of $\sim 83 \mathrm{~km}$ with a rootmean-square (RMS) variability of $\pm 0.9 \mathrm{~km}$. At 05:09 UT the maximum BSC of $20.8 \cdot 10^{-10} / \mathrm{m} / \mathrm{sr}$ is detected at an altitude of $82.3 \mathrm{~km}$. At the lidar wavelength of $770 \mathrm{~nm}$ this BSC corresponds to a Rayleigh signal originating from $\sim 45.5 \mathrm{~km}$ altitude. The NLC lasted in total for more than $11 \mathrm{~h}$ and faded at the end of the observation period which was due to bad weather. Prior to the statistical analysis presented in the next sections we have applied a vertical and temporal filtering of $\pm 200 \mathrm{~m}$ and $\pm 10 \mathrm{~min}$ to the data.

\subsection{Falling spheres and the ROMA campaign}

In summer 2001 a field campaign was conducted close to Longyearbyen. The campaign was part of the ROMA ("Rocket borne Observations in the Middle Atmosphere") project. From 16 July to 14 September 2001, a series of 30 small meteorological rockets were launched from a mobile launcher installed close to Longyearbyen. Here we concentrate on temperature measurements employing the "falling sphere" (FS) technique which is described in detail elsewhere (Schmidlin, 1991; Lübken et al., 1994). This technique gives densities and horizontal winds in an altitude range from approximately 95 down to $30 \mathrm{~km}$. Temperatures are obtained by integrating the density profile assuming hydrostatic equilibrium. A summary of temperatures and densities, and a list of flight dates and labels is presented by Lübken and Müllemann (2003). It should be noted, that the temperature at the top of the FS profile was taken from $\mathrm{K}$ lidar temperature measurements as the 'start temperature' $T_{0}$ in the FS data reduction procedure (see Lübken and Müllemann, 2002, for more details). The K lidar and the rocket launcher were only $\sim 3 \mathrm{~km}$ apart from each other but the actual falling sphere measurements are made at a horizontal distance of approximately $40-50 \mathrm{~km}$ from the launcher. The availability of the $\mathrm{K}$ temperatures significantly improves the FS temperature accuracy in the upper part of the profiles. For example, a typical uncertainty of the $\mathrm{K}$ lidar temperatures at $\sim 95 \mathrm{~km}$ is $\pm 10 \mathrm{~K}$ which includes natural variability and the horizontal
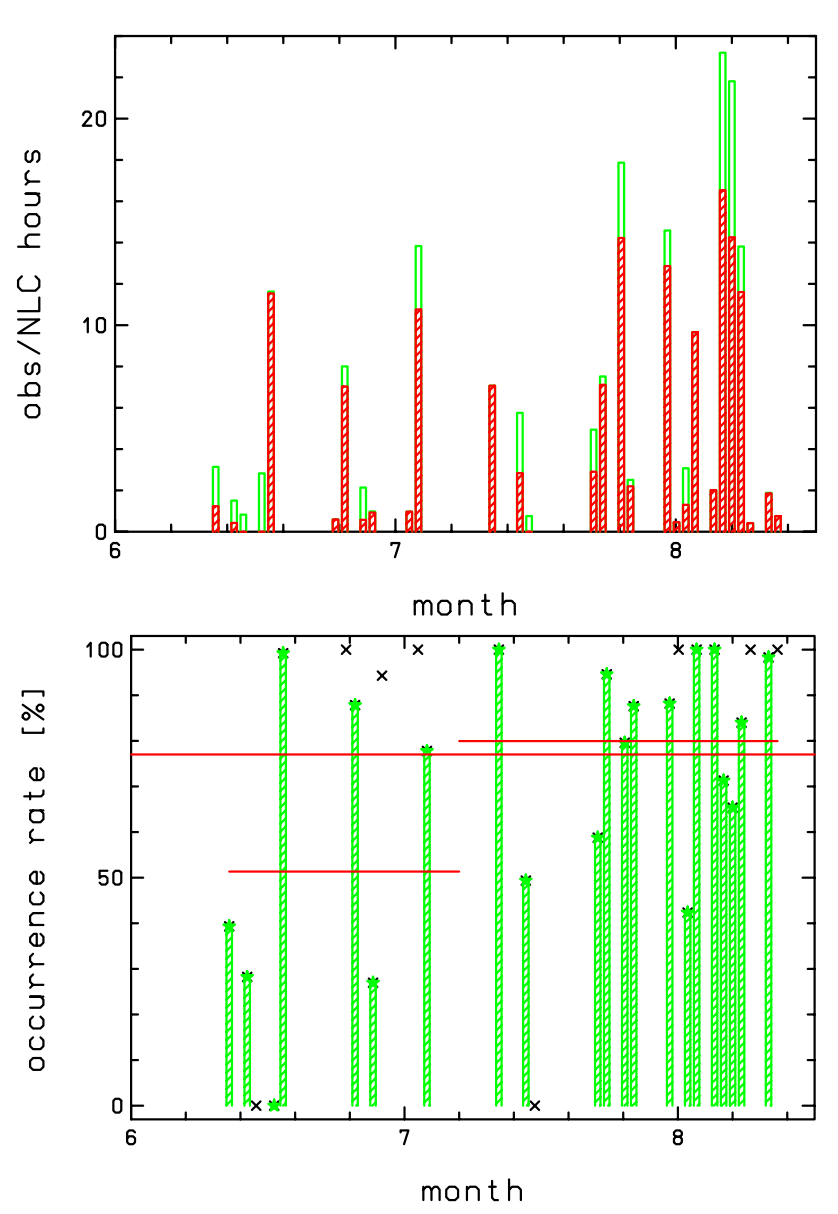

Fig. 2. Daily mean observation statistics for NLC detection by the $\mathrm{K}$ lidar on Spitsbergen. Upper panel: total hours of observation and hours with NLCs (shaded). Lower panel: occurrence frequency of NLCs. Days with little observation time (less than $1 \mathrm{~h}$ ) are marked by crosses only (no vertical bar). Ignoring these days, 3 mean values have been calculated (horizontal lines): one for the entire period and one each for the period 12 June - 4 July and 12 July - 12 August, respectively.

difference of the actual measurements. An uncertainty in $\mathrm{T}_{\mathrm{o}}$ of $\pm 10 \mathrm{~K}$ reduces to $\pm 4,0.8$ and $0.2 \mathrm{~K}$ at 90,85 , and $80 \mathrm{~km}$, respectively. A typical overall uncertainty in temperature at $83 \mathrm{~km}$ is $\pm 4 \mathrm{~K}$, including errors in $\mathrm{T}_{\circ}$ and instrumental effects. The height-dependent sphere reaction time-constant causes a smoothing of the density, temperature, and wind profiles. The smallest scales detectable are typically 8,3 , and $0.8 \mathrm{~km}$ at 85,60 , and $40 \mathrm{~km}$, respectively.

\section{Observations}

\subsection{Noctilucent clouds}

We have analyzed all available backscatter profiles for NLC and found the first occurrence on the first observation day 
Table 1. Details of the NLCs observed by K lidar in Spitsbergen in the summer of 2001

\begin{tabular}{|c|c|c|c|c|c|c|c|c|}
\hline dd & mo & obs-h & NLC-h & $\%$ & z-NLC & z-top & z-bot & BSC \\
\hline 12 & 6 & 3.14 & 1.23 & 39 & 84.1 & 84.8 & 83.1 & 2.1 \\
\hline 14 & 6 & 1.51 & 0.43 & 28 & 83.4 & 84.2 & 82.7 & 0.9 \\
\hline 15 & 6 & 0.83 & 0.00 & 0 & - & - & - & - \\
\hline 17 & 6 & 2.82 & 0.00 & 0 & - & - & - & - \\
\hline 18 & 6 & 11.63 & 11.54 & 99 & 83.6 & 85.1 & 82.7 & 3.7 \\
\hline 25 & 6 & 0.59 & 0.59 & 100 & 86.1 & 87.3 & 84.7 & 3.2 \\
\hline 26 & 6 & 8.00 & 7.03 & 88 & 83.3 & 84.5 & 82.6 & 5.6 \\
\hline 28 & 6 & 2.14 & 0.58 & 27 & 82.5 & 82.8 & 82.3 & 2.3 \\
\hline 29 & 6 & 0.98 & 0.93 & 94 & 84.2 & 84.8 & 83.6 & 1.4 \\
\hline 3 & 7 & 0.97 & 0.97 & 100 & 84.8 & 87.3 & 82.6 & 2.3 \\
\hline 4 & 7 & 13.83 & 10.76 & 78 & 83.7 & 85.3 & 82.7 & 4.5 \\
\hline 12 & 7 & 7.07 & 7.07 & 100 & 83.7 & 85.6 & 82.3 & 10.9 \\
\hline 15 & 7 & 5.75 & 2.84 & 49 & 83.5 & 85.1 & 82.8 & 4.3 \\
\hline 16 & 7 & 0.76 & 0.00 & 0 & - & - & - & - \\
\hline 23 & 7 & 4.94 & 2.90 & 59 & 83.3 & 84.9 & 82.4 & 5.5 \\
\hline 24 & 7 & 7.52 & 7.11 & 95 & 85.2 & 86.2 & 84.3 & 1.2 \\
\hline 26 & 7 & 17.87 & 14.22 & 80 & 83.2 & 84.8 & 82.2 & 2.6 \\
\hline 27 & 7 & 2.51 & 2.20 & 88 & 83.3 & 84.2 & 82.4 & 1.0 \\
\hline 31 & 7 & 14.59 & 12.86 & 88 & 83.2 & 84.6 & 82.2 & 3.3 \\
\hline 1 & 8 & 0.46 & 0.46 & 100 & 83.4 & 84.1 & 82.8 & 3.8 \\
\hline 2 & 8 & 3.07 & 1.30 & 42 & 81.6 & 82.4 & 80.8 & 6.2 \\
\hline 3 & 8 & 9.66 & 9.66 & 100 & 83.8 & 86.1 & 82.6 & 2.5 \\
\hline 5 & 8 & 2.02 & 2.02 & 100 & 84.1 & 85.9 & 82.0 & 1.3 \\
\hline 6 & 8 & 23.19 & 16.53 & 71 & 83.5 & 84.9 & 82.3 & 4.1 \\
\hline 7 & 8 & 21.81 & 14.25 & 65 & 83.6 & 85.3 & 82.3 & 4.1 \\
\hline 8 & 8 & 13.81 & 11.60 & 84 & 83.2 & 84.7 & 82.0 & 4.1 \\
\hline 9 & 8 & 0.41 & 0.41 & 100 & 83.6 & 85.7 & 82.6 & 8.1 \\
\hline 11 & 8 & 1.88 & 1.85 & 98 & 83.1 & 84.8 & 82.1 & 1.8 \\
\hline 12 & 8 & 0.76 & 0.76 & 100 & 83.6 & 84.9 & 83.2 & 1.2 \\
\hline
\end{tabular}

$\mathrm{dd}=$ day; mo=month; obs-h=total observation hours; NLC-h=hours with NLC;

$\%=$ occurence rate; $\mathrm{z}-\mathrm{NLC}=$ mean NLC peak altitude; $\mathrm{z}$-top=top of NLC;

$\mathrm{z}$-bot=bottom of NLC; BSC=volume backscatter coefficient $\left[10^{-10} / \mathrm{m} / \mathrm{sr}\right]$

(12 June) and the last on 12 August. Note, that the lidar was out of operation for a significant part of the campaign because of bad weather. The first measurements after $12 \mathrm{Au}$ gust were made on 26 August and no NLC was observed. In the following we will refer to the time period 12 June until 12 August as the "lidar NLC period". The total number of observing hours in the lidar NLC period was $184.5 \mathrm{~h}$ (5894 profiles) and noctilucent clouds were detected during $142.1 \mathrm{~h}$ (4549 profiles), i.e. during $77 \%$ of the time. We have analyzed the NLC layers in time slots of $24 \mathrm{~h}$ centered around midnight. The result of this analysis is presented in Table 1. As can be seen from Fig. 2 the daily mean occurrence rate varies between 0\% (no NLC) and 100\% (permanent NLC). Ignoring days with little observation time (i.e. less than $1 \mathrm{~h}$ ) the scatter of the occurrence rates is $\pm 30 \%$. We have analyzed the daily mean occurrence rates in two subsets, namely in the period 12 June - 4 July, and 12 July - 12 August, respectively. There are 8 days with little observation time (less than 1 hour). Ignoring these days we find mean occurrence rates of $51 \%$ and $80 \%$ with a RMS variability of $\pm 34 \%$ and $\pm 19 \%$, respectively. We have also examined the occurrence frequency in a different manner, namely by summing up all times with and without NLC in the first and second subset (no pre-calculation for each day). Now, the total occurrence rates are more equal in both subsets: $74 \%$ compared to $78 \%$. While strong NLCs (peak BSC $>5 \times 10^{-10} / \mathrm{m} / \mathrm{sr}$ ) are evenly distributed (18/19\%), medium NLCs (BSC 2-5) are more frequent in the first period $(38 / 25 \%)$ and the occurence of weak NLCs increases (18/35\%). At least part of this increase is probably due to the fact that the performance of the $\mathrm{K}$ lidar was improved throughout the campaign and the solar elevation is lowered which led to a sensitivity increase by a factor of 2-3. We note that more days of observations are available in the second half of the NLC season.

In Fig. 3 the daily mean NLC peak altitudes are shown. Ignoring days where the observation period is less than $1 \mathrm{~h}$ 


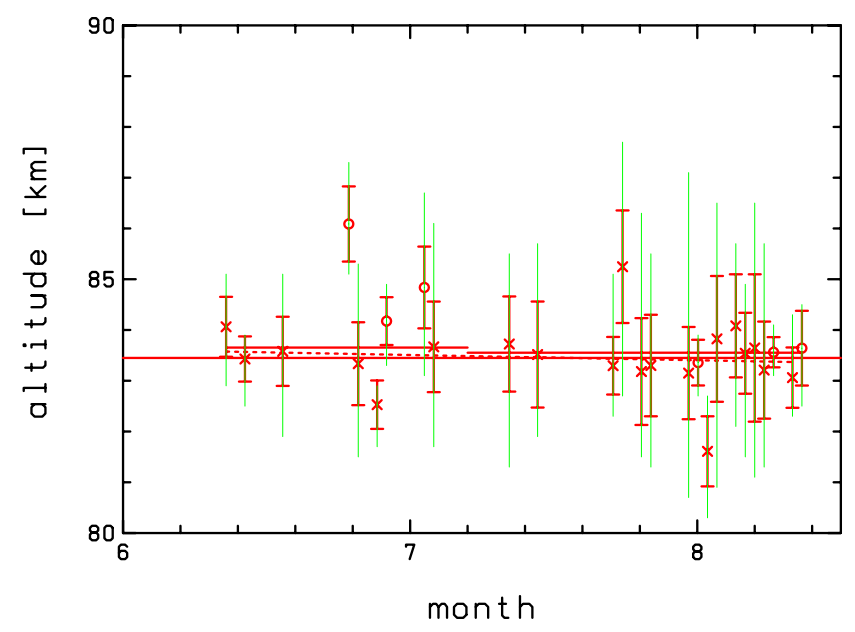

Fig. 3. Daily mean NLC peak altitudes versus month. The crosses indicate the mean altitude of maximum volume backscatter coefficient $\beta_{\max }$ (circles if observation time is less than $1 \mathrm{~h}$ ). The thick error bars present the RMS variability of $\beta_{\max }$ and the thin vertical lines indicate the upper-most and lower-most appearance of the NLC layer during that particular day. The solid horizontal lines give the mean altitudes for the entire period and for the subsets described in the text, respectively. The dashed line is the straight line fitted to the $\beta_{\max }$ values.

the average NLC peak altitude determined from the daily means is $83.4 \mathrm{~km}$. The mean of all individual NLC peak altitudes (without pre-averaging) is $83.6 \mathrm{~km}$, i.e. practically the same value. This demonstrates that the daily mean altitudes are representative for the entire data set. The RMS variation of the mean NLC altitude is $1.1 \mathrm{~km}$. The median of the daily NLC peak altitudes is $83.5 \mathrm{~km}$, i.e. very similar to the mean. The distribution of all individual NLC peak altitudes is shown in Fig. 4. The width of the distribution (FWHM) corresponding to a normal distribution is $2.8 \mathrm{~km}$. We have fitted a Gaussian separately to the lower and upper part of the distribution keeping the maximum value at an altitude of $83 \mathrm{~km}$ fixed. We find half widths (FWHM) of 1.9 and $3.5 \mathrm{~km}$, respectively. This indicates that the NLC peak altitudes extend to somewhat higher altitudes above the mean (compared to below). For comparison with measurements at other latitudes we have also determined the centroid altitudes $\left(z_{c}=\sum(\beta \cdot z) / \sum \beta\right)$ of each NLC profile. The mean of all these centroid altitudes is of $83.7 \pm 1.0 \mathrm{~km}$. Furthermore, we have calculated the "center of half width" defined in Fiedler et al., 2002 and arrive at a mean value of $83.6 \mathrm{~km}$ (RMS variability is $1.1 \mathrm{~km}$ ), again close to the mean of the NLC peak altitudes.

We have analyzed the NLC data in the two subsets mentioned above and found the mean of the individual NLC peak altitudes at $83.6 \pm 0.9 \mathrm{~km}$ and $83.5 \pm 1.2 \mathrm{~km}$, respectively. This indicates that there is no significant NLC height difference in these subsets which is also evident from the slope

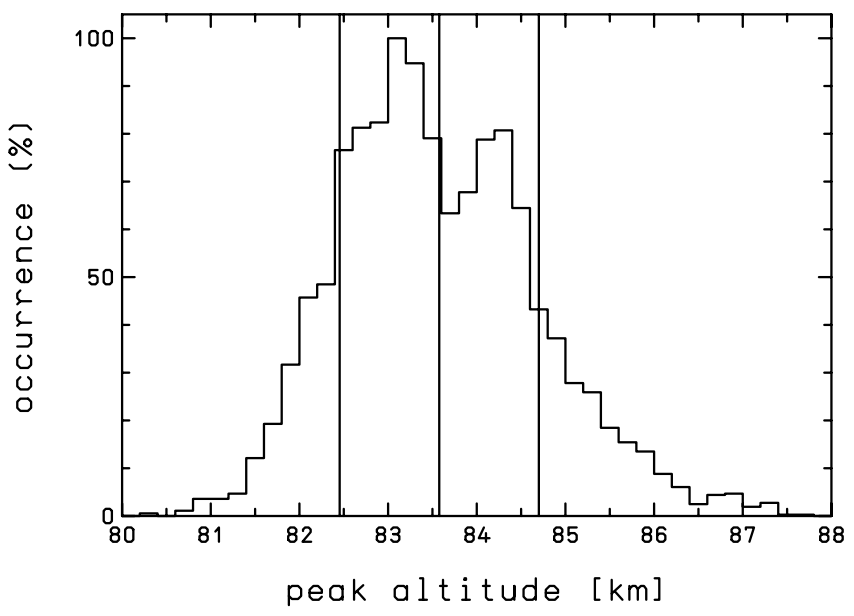

Fig. 4. Histogram of NLC peak altitudes normalized to $100 \%$ for maximum occurrence. The solid vertical lines indicate the mean and the RMS variability of the NLC peak altitudes, respectively.

of a straight line fitted to the daily mean peak altitudes in Fig. 3 which is small $(-0.10 \mathrm{~km} / \mathrm{month})$ and not significant (uncertainty: $\pm 0.25 \mathrm{~km} /$ month). For each NLC profile we have determined the uppermost ("top") and the lowermost ("bottom") altitude of the NLC layer. The average top and bottom altitude calculated from all individual NLC profiles is 85.1 and $82.5 \mathrm{~km}$, respectively (RMS variation: $\sim 1.2 \mathrm{~km}$ ). The mean layer thickness (FWHM) is $1.7 \mathrm{~km}$ (variability: $0.9 \mathrm{~km})$.

The upper edge of the NLC layer is always located below the lower edge of the potassium layer, as in the example of Fig. 1. There is no case of a NLC reaching above the lower edge of the potassium layer or appearing (with $\beta>10^{-10} / \mathrm{m} / \mathrm{sr}$ ) inside. This suggests that there are no very weak NLC present inside the K layer which we could have missed due to the somewhat reduced sensitivity to detect NLCs inside the K layer. We therefore argue that our statistics on the altitude and occurrence distribution for weak NLCs is not influenced by the decreased sensitivity inside the K layer.

We have also analyzed the statistical properties of the maximum volume backscatter coefficient $\left(\beta_{\max }\right)$ at our wavelength of $770 \mathrm{~nm}$. The mean $\beta_{\max }$ for the entire season determined from all individual NLC profiles (ignoring profiles with no NLC) is $3.9 \times 10^{-10} / \mathrm{m} / \mathrm{sr}$ with a large RMS variability of nearly $100 \%$. Again, we have analyzed the NLC data in the two subsets mentioned above and found mean values for $\beta_{\max }$ of 4.1 and 3.8 with a RMS variability of 3.0 and 4.1, respectively (all values in units of $10^{-10} / \mathrm{m} / \mathrm{sr}$ ). This implies that there is no significant change of the maximum BSC in these subsets. We note that the measurement of the maximum BSC does not depend on the lidar sensitivity as long as $\beta_{\max }$ is significantly above the detection threshold. With the increased sensitivity of the lidar (see above) more weak 

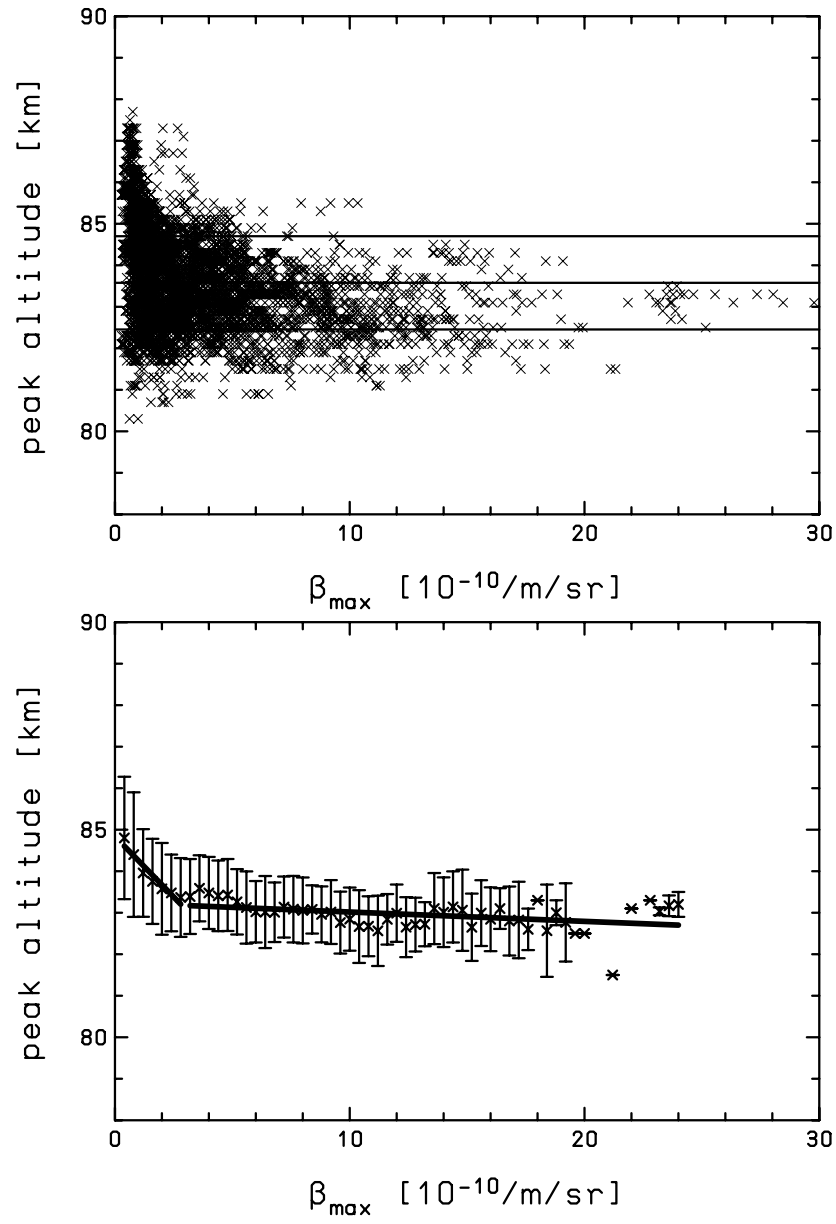

Fig. 5. Scatter plot of the maximum volume backscatter coefficient $\beta_{\max }$ versus peak altitude for all individual profiles (upper panel). The solid horizontal lines indicate the mean and the RMS variability of the NLC peak altitudes. In the lower panel the peak altitudes are averaged in BSC bins of width $0.4 \cdot 10^{-10} / \mathrm{m} / \mathrm{sr}$. The vertical lines indicate the variability in each bin. Two straight lines have been fitted (thick solid lines in lower panel) namely for $\beta_{\max }$ values smaller and larger than 3, respectively.

NLCs are included in the statistics and a somewhat lower mean value is expected for the second subset.

Another characteristic of NLC layers that can be compared with models is the distribution of $\beta_{\max }$ with altitude. For example, from steady state considerations of NLC growth and sedimentation it is sometimes taken for granted that the strongest NLCs occur at lowest heights. In Fig. 5a we present a scatter plot of all individual $\beta_{\max }$ values versus peak altitudes. Indeed, there is a weak tendency for brighter NLCs to occur at lower altitudes and this trend varies with $\beta_{\max }$. To arrive at more quantitative results we have averaged the peak altitudes in $\beta_{\max }$-bins of $0.4 \times 10^{-10} / \mathrm{m} / \mathrm{sr}$ and have fitted two straight lines, namely for small $\beta_{\max }$ values (up to 3 ) and for larger $\beta_{\max }$ (see Fig. 5b). At small $\beta_{\max }$ values the slope of a regression line is $-0.58 \pm 0.08$. The slope at larger
Table 2. Simultaneous measurements by K lidar and falling spheres during ROMA, 2001

\begin{tabular}{cccc}
\hline $\begin{array}{c}\text { flight } \\
\text { label }\end{array}$ & $\begin{array}{c}\text { date, time } \\
(\mathrm{UT})\end{array}$ & $\begin{array}{c}\text { potassium lidar period } \\
\text { dates and times (UT) }\end{array}$ & NLC \\
\hline (ROFS03) & 22 Jul. 12:20 & 22 Jul 23:48-23 Jul 19:47 & yes \\
(ROFS05) & 25 Jul. 10:00 & 25 Jul 14:31-26 Jul 14:37 & yes \\
ROFS07 & 31 Jul. 09:00 & 30 Jul 16:11-31 Jul. 12:00 & yes \\
ROFS09 & 02 Aug. 18:00 & 02 Aug 08:24-02 Aug 21:45 & yes \\
ROFS10 & 06 Aug. 09:38 & 05 Aug 09:52-08 Aug 01:54 & yes \\
ROFS18 & 27 Aug. 10:45 & 26 Aug 09:37-28 Aug 02:00 & no \\
\hline
\end{tabular}

The K lidar time period may include a few hours of data interruption due to bad weather. For ROFS03 and ROFS05 the K lidar measurements took place a few hours prior to launch.

$\beta_{\text {max }}$ values is very small $(-0.023 \pm 0.008)$ but still statistically significant (all numbers are in the physical dimensions of Fig. 5).

\subsection{NLCs and falling sphere temperatures}

Simultaneous K lidar measurements and FS temperature profiles are available for 4 flights, where during 3 of these flights a NLC was detected (see Table 2). Two more flights, namely ROFS03 and ROFS05, took place a few hours prior to the closest $\mathrm{K}$ lidar measurements and will therefore not be considered in the following discussion. In Fig. 6 we present the temperature profile from ROFS10 and the corresponding NLC profile averaged for $\pm 1 \mathrm{~h}$ around the rocket launch. Furthermore, two frost point temperature profiles $T_{\text {frost }}$ are shown using water vapor mixing ratio profiles from two different models, namely from Körner and Sonnemann (2001) (K\&S) and from von Zahn and Berger (2003) (vZ\&B). The latter is a 3-dimensional model which includes the effect of freeze drying, i.e. the redistribution of water vapor due to ice particles being formed in the vicinity of the mesopause, and evaporating at lower altitudes. At very high latitudes the two $\mathrm{H}_{2} \mathrm{O}$ profiles are rather similar up to $\sim 85 \mathrm{~km}$ (difference is less than a factor of 2) but deviate by a factor of up to 10 at the mesopause (see Fig. 9 in von Zahn and Berger, 2003). As can be seen from Fig. 6 the actual temperatures are lower then $T_{\text {frost }}$ in an extended altitude range from approximately 82 to $91 \mathrm{~km}$ (depending on $\left[\mathrm{H}_{2} \mathrm{O}\right]$ ) indicating that it is cold enough at these heights for ice particles to grow or to exist. The NLC in Fig. 6 appears at the bottom of the height range where the actual temperatures are smaller than $T_{\text {frost }}$. We will come back to a comparison of NLCs and temperatures in Sect. 4.1 


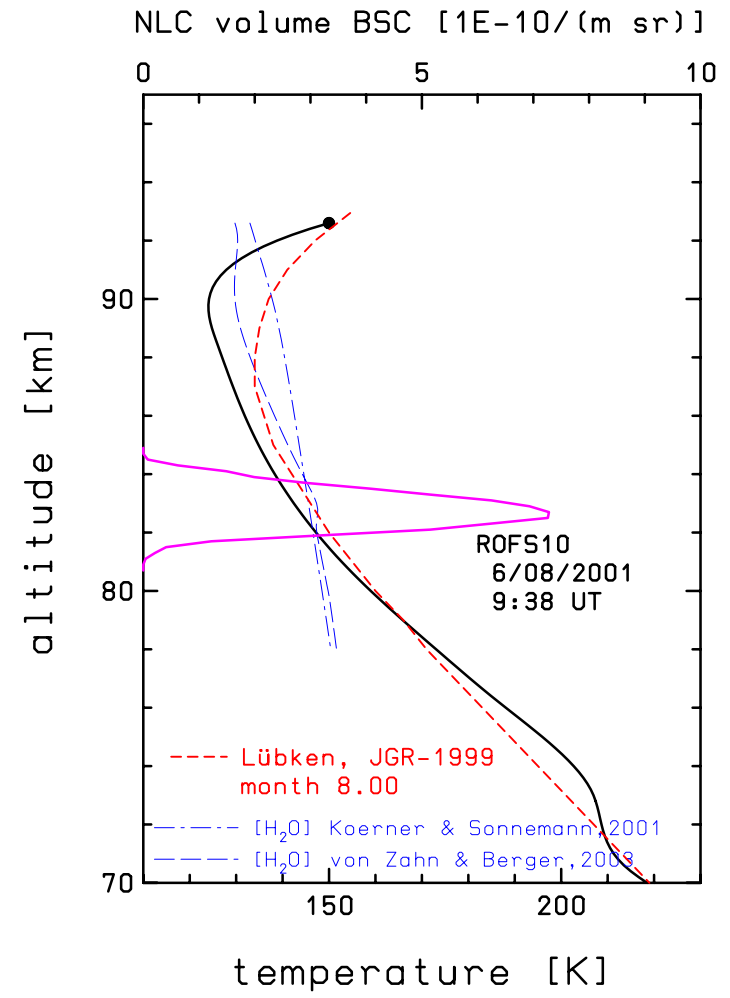

Fig. 6. Temperature profile from flight ROFS10 launched on $6 \mathrm{Au}-$ gust at 09:38 UT (black line) and the NLC volume BSC averaged for $\pm 1 \mathrm{~h}$ around the rocket launch (purple line; upper abscissa). The two blue dashed lines indicate frost point temperatures $T_{\text {frost }}$ using model water vapor mixing ratios from Körner and Sonnemann (2001) and from von Zahn and Berger [2003], respectively. For comparison the profile from FJL-JGR99 for $69^{\circ} \mathrm{N}$ is presented (red dashed line).

\section{Discussion}

\subsection{NLCs and the degree of saturation}

In Fig. 7 two more temperature profiles and the corresponding NLC layers are shown, namely from flights ROFS07 and ROFS09. As in Fig. 6 there are various height ranges with super-saturation $\left(T_{\text {atm }}<T_{\text {frost }}\right)$ in the upper mesosphere, but the NLC appears only in the lower part of these height ranges. We have calculated the degree of saturation $(S)$ at the NLC peak and at the top and the bottom of the layer. The results of these calculations are presented in Table 3. To demonstrate the uncertainty of these values due to the unknown water vapor profile we have determined two $S$ values using water vapor values from $K \& S$ and $v Z \& B$, respectively. As noted before the two model profiles are rather similar up to $\sim 85 \mathrm{~km}$ and deviate substantially above. Subsequently, the effect on the $S$ values depends on altitude and is substantial (more than a factor of 3) only for the NLC top altitude during flight ROFS09. The $S$ values depend strongly on temperature ( $T$ ), i.e. any error in $T$ results in comparatively large
Table 3. Temperatures in the NLC layer

\begin{tabular}{lccc}
\hline & ROFS07 & ROFS09 & ROFS10 \\
\hline $\mathrm{z}_{\text {top }}[\mathrm{km}]$ & 84.5 & 87.3 & 84.5 \\
temperature $[\mathrm{K}]$ & 143 & 121 & 136 \\
$\mathrm{~S}(\mathrm{~K} \& \mathrm{~S})$ & 1.5 & 1500 & 13 \\
$\mathrm{~S}(\mathrm{vZ \& B})$ & 1.0 & 140 & 6 \\
\hline $\mathrm{z}_{\text {peak }}[\mathrm{km}]$ & 82.5 & 84.5 & 82.6 \\
$\beta_{\text {max }}\left[10^{-10} / \mathrm{m} / \mathrm{sr}\right]$ & 4.8 & 3.3 & 7.3 \\
temperature $[\mathrm{K}]$ & 149 & 127 & 144 \\
$\mathrm{~S}(\mathrm{~K} \& S)$ & 0.5 & 380 & 2.3 \\
$\mathrm{~S}(\mathrm{vZ \& B})$ & 0.7 & 180 & 2.8 \\
\hline $\mathrm{z}_{\text {bottom }}[\mathrm{km}]$ & 80.7 & 82.9 & 81.1 \\
temperature $[\mathrm{K}]$ & 157 & 137 & 152 \\
$\mathrm{~S}(\mathrm{~K} \& S)$ & 0.1 & 18 & 0.4 \\
$\mathrm{~S}(\mathrm{vZ \& B})$ & 0.1 & 21 & 0.4 \\
\hline
\end{tabular}

$\mathrm{S}(\mathrm{K} \& \mathrm{~S})$ is the degree of saturation using water vapor mixing ratios from Körner and Sonnemann (2001).

$\mathrm{S}(\mathrm{vZ \& B})$ is the degree of saturation using water vapor mixing ratios from von Zahn and Berger (2003).

errors in $S$. For example, at NLC altitudes an uncertainty in temperature of 2-3 degrees (a typical value at $83 \mathrm{~km}$; see above) corresponds to an uncertainty in $S$ by a factor of 2 .

Some of the $S$ values in Table 3 are smaller than one even if we take into account the uncertainties in $S$ discussed above. This suggests that the particles should disappear due to evaporation. We would like to note, however, that even in a situation of under-saturation it will take some time before an ice particle disappears. For example, with $S=0.5$ and a radius of $20 \mathrm{~nm}$ it takes several hours before the ice particle has completely evaporated (Gadsden, 1981).

As can be seen from Table 3 the degree of saturation at the NLC peak varies substantially and differs significantly from $S=1$. In a simplistic picture one would expect that NLC particles achieve their largest size and produce largest BSC at the $S=1$ level since they grow in the $S>1$ regime while sedimenting through the atmosphere. However, model studies of microphysical processes controlling the generation of NLCs in the presence of gravity waves have shown that (for long period gravity waves) the NLC peak coincides with the $S=1$ level only very seldom and values larger and smaller than $S=1$ will occur. Rapp et al. (2002) found values in the range of about $S=0.2$ to $S=10$. Our observations support this finding even if we take into account the uncertainties about the actual $S$ value discussed above.

For flight ROFS07 a major part of the NLC is located in a region of under-saturation in particular at the bottom of the layer at $80.7 \mathrm{~km}$. We note that large enhancements of water vapor up to 10-15 ppmv have been observed in this altitude range by the HALOE instrument on UARS, though at lower latitudes Summers et al. (2001). This enhancement is pre- 

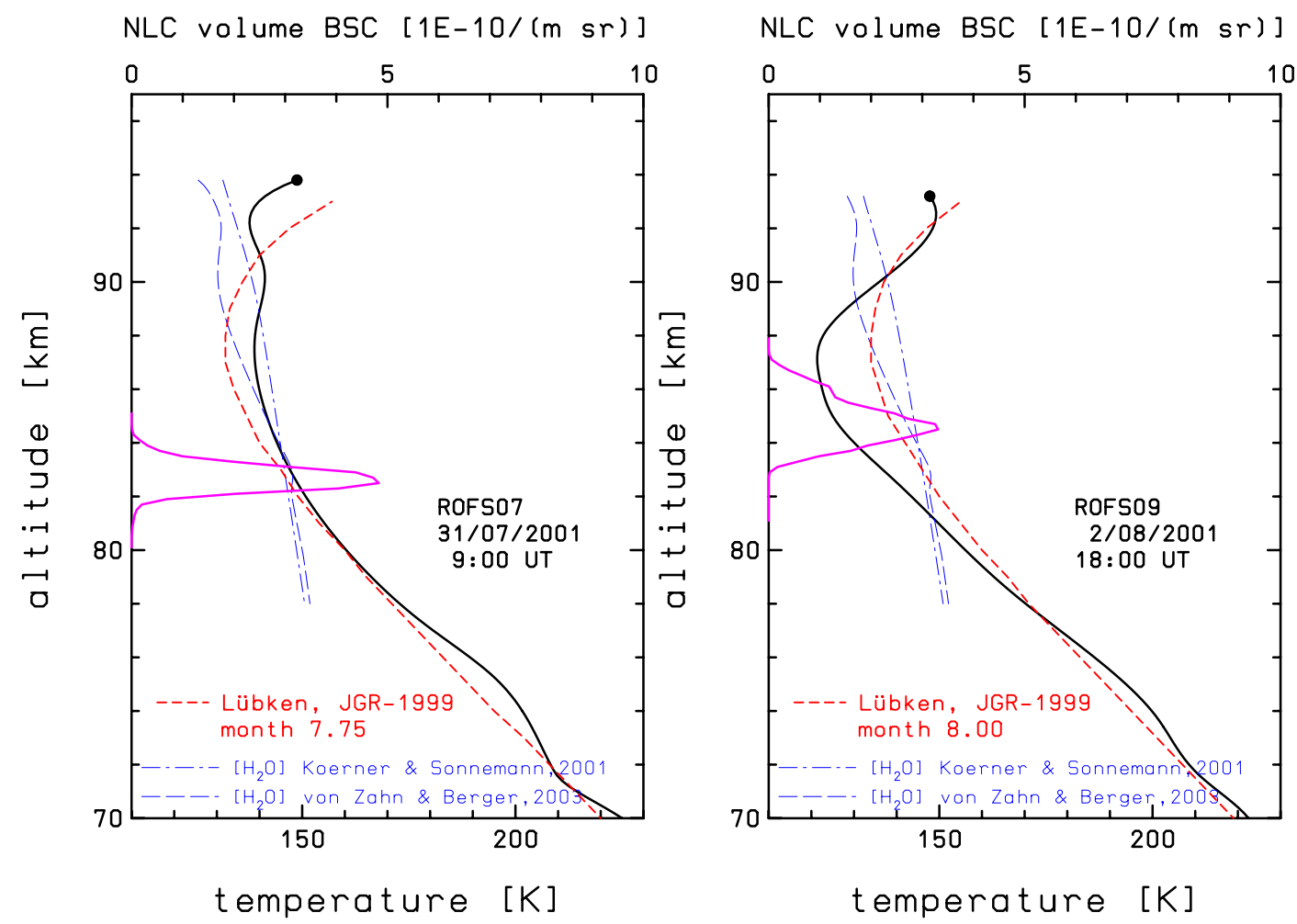

Fig. 7. Same as Fig. 6 but for flights ROFS07 (left panel) and ROFS09 (right panel). The launch dates and times are given in the plots.

sumably caused by the "freeze drying" effect mentioned earlier We can certainly not exclude that the local water vapor concentration during flight ROFS07 deviated largely from the model values. For flight ROFS09, very large $S$ values are found in the entire NLC layer. We conclude that the range of $S$ values in the NLC layer varies greatly and can be larger and smaller than one.

As can also be seen from Table 3 there is no obvious correlation between the degree of saturation and the maximum volume backscatter coefficient $\beta_{\max }$. The peak BSC varies only little and is largest in a case of moderate supersaturation ( $S=2$ for flight ROFS10). This again supports the statement that arguments derived from steady-state assumptions may not be applicable when relating individual NLC properties to the background thermal field. On the other hand, the mean variation of the NLC appearance with height and season is in agreement with the climatological variation of super-saturation derived from the FS temperature measurements (see Fig. 4 in Lübken and Müllemann, 2003). This is true even if we consider the uncertainty $S$ caused by the unknown water vapor concentration discussed above. At the end of our lidar NLC period (12 August, i.e. when measurements had to be terminated due to bad weather) temperatures are still low enough for super-saturation. When the lidar was started again on 26 August temperatures had just become too high for super-saturation and indeed no NLC was observed.
The maximum $S$ values deduced from the FS climatology occur around $87-88 \mathrm{~km}$ and reach values of 26,3 , and 0.2 for 15 August, 23 August, and 1 September, respectively, using $\mathrm{H}_{2} \mathrm{O}$ values from $\mathrm{K} \& \mathrm{~S}$. Similar values for the model of vZ\&B can not be given because this model depends not on season. This indicates that at 26 August (time $=8.84$ ) climatological temperatures are too high for the creation of NLCs. We conclude that there is a very close correspondence of the general morphology of NLCs and the local thermal structure over Spitsbergen allowing for super-saturation, in spite of the large time constants (hours) which are associated with large horizontal transport distances (Berger and von Zahn, 2002).

In summary, NLCs appear in the lower part of the height range of super-saturation but details of their morphology (BSC, layer width etc.) do not depend on the local thermal structure. This is in line with model results which suggest that it can take several hours before an ice particle reaches a size detectable by lidar (Berger and von Zahn, 2002; Rapp et al., 2002). During this time the particle is carried hundreds of kilometers by the mean wind and the background conditions relevant for ice particle formation, e.g. temperatures and vertical winds, have most likely varied. On the other hand, the mean variation of the NLC appearance with height and season is in nice agreement with the climatological variation of the thermal structure in the upper mesosphere. 


\subsection{Comparison of NLCs with other latitudes}

The characteristics of NLCs observed by the R/M/R-lidar at ALOMAR $\left(69^{\circ} \mathrm{N}\right)$ have recently been summarized by Fiedler et al. (2002) based on data from 5 summer seasons. Technical details of the lidar are described in von Zahn et al. (2000). Although our statistics are poorer compared to ALOMAR we will now compare the main NLC features at both sites. The analysis of Fiedler et al. was performed in 5 time periods of 15 days each. Our lidar NLC period at Spitsbergen is best represented by their periods 2-5 (16 June - 15 August).

The NLC occurrence frequency at ALOMAR varies from year to year and is in the range $\sim 30-50 \%$. This is considerably less compared to Spitsbergen (77\%). In the year of our measurements (2001) the mean occurrence frequency at ALOMAR is $28 \%$ which is less than half compared to Spitsbergen. To avoid an instrumental bias in these values we compare the rates derived for NLCs which are stronger than a threshold of $\beta_{\max }>4$ which is clearly above the detection limit of the ALOMAR lidar. The occurence rate then ranges between 20 and 30\%, with the lower value observed in 2001 . Using a corresponding threshold of $\beta_{\max }>1.25$ at $770 \mathrm{~nm}$ (see below), which is above our instrumental limit, we obtain an occurence rate of $61 \%$, again more than twice the value from $69^{\circ} \mathrm{N}$. This occurrence increase of NLCs with latitude is in line with the increase of polar mesospheric cloud (PMC) frequency observed by satellites (Thomas et al., 1991).

The mean center NLC altitude $z_{c}$ at ALOMAR varies little in periods $2-5$ and is approximately $83.3 \mathrm{~km}$ (variability: $\pm 1.2 \mathrm{~km}$ ) which is very similar to our value of $83.6 \mathrm{~km}$. The center altitude at ALOMAR has increased since 1997 and reaches $\sim 83.9 \mathrm{~km}$ in 2001 , thus varying about the value at Svalbard. Fiedler et al. (2002) find only very little seasonal variation of $z_{c}$, again very similar to our observations at Spitsbergen. The mean width of $1.3 \mathrm{~km}$ at ALOMAR is slightly less compared to Spitsbergen $(1.7 \mathrm{~km})$.

The maximum BSC at ALOMAR has decreased since 1997 and reached a mean of $\beta_{\max }=9 \cdot 10^{-10} / \mathrm{m} / \mathrm{sr}$ in 2001 . This value is slightly larger (9.6) if the same time period in 2001 is taken at ALOMAR compared to our campaign period at Spitsbergen. Please note that there exist large differences between mean, median and mode values for $\beta_{\max }$ as is described in more detail in Fiedler et al. (2002).

When comparing NLC strengths measured by different lidars the wavelength dependence of the backscatter coefficient must be taken into account. The ratio of the BSCs at two wavelengths is called "color ratio" and depends strongly on the particle mode radius $r_{m}$ and on the size distribution. We assume a lognormal size distribution of spherical ice particles with $r_{m}=40 \mathrm{~nm}$ and a width of $\sigma=1.4$. We then arrive at color ratios of 3.2 and 7.3 for $532 \mathrm{~nm} / 770 \mathrm{~nm}$ and $374 \mathrm{~nm} / 770 \mathrm{~nm}$, respectively. These ratios need to be applied for the comparison of our results with the R/M/Rlidar at ALOMAR and the Fe lidar at the South pole (see later). Taking into account this color ratio the ALOMAR value of $\beta_{\max }=9.6$ (see above) corresponds to a $\beta_{\max }$ of $3.0 \cdot 10^{-10} / \mathrm{m} / \mathrm{sr}$ at $770 \mathrm{~nm}$ which is slightly but not significantly less compared to the Spitsbergen mean of $\beta_{\max }=$ $3.9 \cdot 10^{-10} / \mathrm{m} / \mathrm{sr}$. We note that the color ratio varies substantially (from approximately $2.5-4.5$ ) if other particle radii and widths are assumed. Therefore we conclude, that the brightness of the NLCs at ALOMAR and at Spitsbergen do not deviate significantly.

In summary, the mean NLC characteristics at two sites separated by almost 10 degrees in latitude, namely ALOMAR at $69^{\circ} \mathrm{N}$ and Spitsbergen at $78^{\circ} \mathrm{N}$, are similar with respect to the peak altitude and the maximum volume backscatter coefficient, but differ significantly with respect to the occurrence frequency (larger at higher latitudes).

Chu et al. (2002) have recently presented NLC results obtained with their Fe Boltzmann lidar $(374 \mathrm{~nm})$ at the South Pole during the summer seasons of 1999/2000 and 2000/2001. Their coverage of the summer season is similar to our "lidar NLC period" (12 June to 12 August which corresponds to day numbers after solstice of -9 and 52, respectively) with a somewhat better coverage at the beginning of the NLC season. Taking mean values from both years the centroid altitude $z_{c}$ at the South pole is approximately $85.0 \mathrm{~km}$, i.e. $\sim 1.3 \mathrm{~km}$ higher compared to Spitsbergen. It should be noted, however, that $z_{c}$ varies by approximately $1 \mathrm{~km}$ in the two years of observations at the South pole. We do not detect a decrease of NLC altitudes at the end of the season as stated in Chu et al. (2002). The NLC occurrence frequency at the South pole is somewhat smaller (67\%) compared to Spitsbergen, but the difference is within the natural variability observed during our NLC season $( \pm 28 \%)$.

The mean of the maximum backscatter coefficients $\beta_{\text {max }}$ at the South pole is $37 \cdot 10^{-10} / \mathrm{m} / \mathrm{sr}$ at $374 \mathrm{~nm}$. This corresponds to 5.1 at $770 \mathrm{~nm}$ taking the color ratio into account (see above). This is somewhat larger compared to the mean value at Spitsbergen (3.9). However, the difference is within the uncertainty of the color ratio caused by the unknown mean particle radius and size distribution.

\section{Conclusion and outlook}

We have presented the first lidar observations of noctilucent clouds at Spitsbergen and have discussed in detail the statistical properties of the NLC layer height, strength etc. We have compared these results with the thermal structure of the background field deduced from falling sphere measurements. The NLC altitudes and strengths at Spitsbergen are similar to ALOMAR $\left(10^{\circ}\right.$ further south) but NLCs are more frequent at Spitsbergen.

The comparison of FS temperatures and NLCs demonstrates that arguments derived from steady-state assumption may not be applicable when relating individual NLC properties to the background thermal field. On the other hand, 
the mean variation of the NLC appearance with height and season is in nice agreement with the climatological variation of the thermal structure in the upper mesosphere. This local agreement between the mean appearance of NLCs and the conditions set by the background atmosphere is important for comparison with models which take into account the time constant of hours for the generation of NLC particles and the corresponding large horizontal transport distances. We will continue and complete our measurements in the next years to explore inter-annual variability and improve the statistics of NLCs at very high latitudes.

Acknowledgements. We thank Mrs. Liu, Mr. Menzel, and Mr. Lautenbach for their assistance during the lidar operation. The support of the Svalsat team during installation and maintenance of the lidar in Spitsbergen is gratefully acknowledged. We thank A. Müllemann for the FS data processing and G. Baumgarten and M. Alpers for the color ratio calculations. J. Fiedler has kindly provided results for the comparison with the ALOMAR data. The ROMA project is supported by the Bundesministerium für Bildung, Wissenschaft, Forschung und Technologie, Bonn, under grants 50 OE 9901 and 07 ATF 10.

\section{References}

Alpers, M., Gerding, M., Höffner, J., and von Zahn, U.: NLC particle properties from a five-color observation at $54^{\circ} \mathrm{N}$, J. Geophys. Res., 105, 12 235-12 240, 2000.

Baumgarten, G., Lübken, F. J., and Fricke, K. H.: First observation of one noctilucent cloud by a twin lidar in two different directions, Ann. Geophysicae, 20, 1863-1868, 2002.

Berger, U. and von Zahn, U.: Icy particles in the summer mesopause region: 3-dim modeling of their environment and 2-dim modeling of their transport, J. Geophys. Res., 107, doi. 10.1029/2001JA00316, 2002.

Chu, X., Gardner, C., and Papen, G.: Lidar observations of polar mesospheric clouds at south pole: seasonal variations, Geophys. Res. Lett., 28, 1203-1206, 2001.

Chu, X., Gardner, C., and Roble, R.: Lidar studies of interannual, seasonal and diurnal variations of polar mesospheric clouds at the South pole, J. Geophys. Res., 108, 8447, doi. 10.1029/2002JD002524, 2002.

Fiedler, F., Baumgarten, G., and von Cossart, G.: Noctilucent clouds above ALOMAR between 1997 and 2001: Occurrence and properties, J. Geophys. Res., doi. 10.1029/2002JD002419, 2002.

Fleming, E. L., Chandra, S., Barnett, J. J., and Corney, M.: Zonal mean temperature, pressure, zonal wind, and geopotential height as functions of latitude, Adv. Space Res., 10, 12, 11-59, 1990.

Fricke-Begemann, C., Alpers, M., and Höffner, J.: Daylight rejection with a new receiver for potassium resonance temperature lidars, Opt. Lett., 27, 21, 1932-1934, 2002.

Fritts, D. C., Isler, J. R., Thomas, G. E., and Andreassen, Ø.: Wave breaking signatures in noctilucent clouds, Geophys. Res. Lett., 20, 2039-2042, 1993.

Gadsden, M.: The north-west Europe data on noctilucent clouds: a survey, J. Atmos. Sol.-Terr. Phys., 60, 1163-1174, 1998.
Gadsden, M. and Schröder, W.: Noctilucent clouds, SpringerVerlag, New York, 1989.

Gadsden, M.: The silver-blue cloudlets again: nucleation and growth of ice in the mesosphere, Planet. Space Sci., 29, 10791087, 1981.

Garcia, R. R.: Dynamics, radiation and photochemistry in the mesosphere: Implications for the formation of noctilucent clouds, J. Geophys. Res., 94, 14605-14 615, 1989.

Hansen, G., Serwazi, M., and von Zahn, U.: First detection of a noctilucent cloud by lidar, Geophys. Res. Lett., 16, 1445-1448, 1989.

Jensen, E. and Thomas, G. E.: A growth-sedimentation model of polar mesospheric clouds: Comparions with SME measurements, J. Geophys. Res., 93, 2461-2473, 1988.

Jesse, O.: Die leuchtenden Nachtwolken, Meteorol. Zeitung, 6, 184-186, 1889.

Kirkwood, S. and Stebel, K.: The influence of planetary waves on noctilucent cloud occurrence over NW Europe, J. Geophys. Res., 108, doi. 10.1029/2002JD002356, 2003.

Klostermeyer, J.: A simple model of the ice particle size distribution in noctilucent clouds, J. Geophys. Res., 103, 28 743-28 752, 1998.

Körner, U. and Sonnemann, G. R.: Global 3D-modeling of the water vapor concentration of the mesosphere/mesopause region and implications with respect to the NLC region, J. Geophys. Res., 106, 9639-9651, 2001.

Leslie, R.: Sky glows, Nature, 32, 245, 1885.

Lübken, F.-J.: Thermal structure of the Arctic summer mesosphere, J. Geophys. Res., 104, 9135-9149, 1999.

Lübken, F.-J.: Nearly zero temperature trend in the polar summer mesosphere, Geophys. Res. Lett., 27, 3603-3606, 2000.

Lübken, F.-J. and Müllemann, A.: First in situ temperature measurements in the summer mesosphere at very high latitudes $\left(78^{\circ} \mathrm{N}\right)$, J. Geophys. Res., 108, doi. 10.1029/2002JD002414, 2003.

Lübken, F.-J., Hillert, W., Lehmacher, G., von Zahn, U., Bittner, M., Offermann, D., Schmidlin, F., Hauchecorne, A., Mourier, M., and Czechowsky, P.: Intercomparison of density and temperature profiles obtained by lidar, ionization gauges, falling spheres, datasondes, and radiosondes during the DYANA campaign, J. Atmos. Terr. Phys., 56, 1969-1984, 1994.

Lübken, F.-J., Fricke, K.-H., and Langer, M.: Noctilucent clouds and the thermal structure near the Arctic mesopause, J. Geophys. Res., 101, 9489-9508, 1996.

Lübken, F.-J., Höffner, J., Fricke-Begemann, C., Müllemann, A., Zecha, M., and Röttger, J.: Mesospheric layers and temperatures at Spitsbergen, $78^{\circ} \mathrm{N}$, in Proceedings of the "Mesospheric Clouds" meeting, edited by Gadsden, M., British Astronomical Association, Perth, Scottland, 2002.

Rapp, M., Lübken, F.-J., Müllemann, A., Thomas, G. E., and Jensen, E. J.: Small scale temperature variations in the vicinity of NLC: Experimental and model results, J. Geophys. Res., 107, doi. 10.1029/2001JD001241, 2002.

Schmidlin, F. J.: The inflatable sphere: A technique for the accurate measurement of middle atmosphere temperatures, J. Geophys. Res., 96, 22,673-22,682, 1991.

Summers, M. E., Conway, R. R., Englert, C. R., Siskind, D. E., Stevens, M. H., Russell, J. M., Gordley, L. L., and McHugh, M. J.: Discovery of a water vapor layer in the Artic summer mesosphere: Implications for Polar mesospheric clouds, Geo- 
phys. Res. Lett., 28, 3601-3604, 2001.

Thayer, J., Rapp, M., Gerrard, A., Gudmundsson, E., and Kane, T.: Grawity Wave Influences on Arctic Mesospheric Clouds as Determined by the Sondrestrom, Greenland, Rayleigh Lidar, J. Geophys. Res., 107, doi. 10.1029/2002JD002363, 2002.

Thomas, G. E., Olivero, J. J., Jensen, E. J., Schroeder, W., and Toon, O. B.: Relation between increasing methane and the presence of ice clouds at the mesopause, Nature, 338, 490-492, 1989.

Thomas, G. E., McPeters, R. D., and Jensen, E. J.: Satellite observations of polar mesospheric clouds by the solar backscattered ultraviolet spectral radiometer: evidence of a solar cycle dependence, J. Geophys. Res., 96, 927-939, 1991.

von Cossart, G., Fiedler, J., and von Zahn, U.: Size distributions of NLC particles as determined from 3-color observations of NLC by ground-based lidar, Geophys. Res. Lett., 26, 1513-1516, 1999. von Zahn, U. and Berger, U.: Persistent ice cloud in the midsummer upper mesosphere at high latitudes: Three-dimensional modeling and cloud interactions with ambient water vapor, J. Geophys. Res., 108, 8451, doi. 10.1029/2002JD002409, 2003.

von Zahn, U. and Höffner, J.: Mesopause temperature profiling by potassium lidar, Geophys. Res. Lett., 23, 141-144, 1996.

von Zahn, U. and Meyer, W.: Mesopause temperatures in polar summer, J. Geophys. Res., 94, 14 647-14 651, 1989.

von Zahn, U., von Cossart, G., and Fiedler, J.: Tidal variations of noctilucent clouds measured at $69^{\circ} \mathrm{N}$ latitude by ground based lidar, Geophys. Res. Lett., 25, 1289-1292, 1998.

von Zahn, U., von Cossart, G., Fiedler, J., Fricke, K. H., Nelke, G., Baumgarten, G., Rees, D., Hauchecorne, A., and Adolfsen, K.: The ALOMAR Rayleigh/Mie/Raman lidar: Objectives, configuration, and performance, Ann. Geophysicae, 18, 815-833, 2000. 